\section{Cancer research in South African academic and research institutions}

To the Editor: A valuable overview of cancer research in South African (SA) academic and research institutions during 2013 - 2014 has recently been published. ${ }^{[1]}$ The titles of 556 research projects were reviewed and divided into basic science, clinical and public health domains. These domains contained $46 \%, 54 \%$ and $13 \%$ of the projects, respectively. The projects could fit into more than one domain, resulting in a total of $113 \%$.

The authors rightly note the relative dearth of projects on public health - only $13 \%$ of all projects. These studies are important for cancer prevention, early diagnosis and cost-effective management. However, these findings also suggest that there is a need for an increase in joint projects by researchers in all the domains. Only 13\% of all projects were in more than one domain. Both basic scientists and clinical researchers may contribute to translational research, which is key to understanding the scientific basis of cancer control programmes.

SA has a proud and productive history of collaboration between researchers. Examples are the linking of asbestos exposure to mesothelioma and the initial development of computed tomo- graphy. ${ }^{[2]}$ The research community will promote joint projects by having regular meetings of basic science, clinical and public health representatives, which aim to bring together fellow researchers with common interests but different backgrounds. We can complement face-to-face meetings with virtual meetings at a low cost. These could take place within universities, within regions or nationally. The latter would be particularly valuable in SA, with its varied regions and mix of established and new universities.

Research to improve healthcare thrives on synergy as well as scientific rigour.

\section{R P Abratt}

Head of Clinical Governance, Independent Clinical Oncology Network, South Africa; and Emeritus Professor of Radiation Oncology, Faculty of Health Sciences, University of Cape Town, South Africa

raymond.abratt@cancernet.co.za

1. Moodley J, Stefan DC, Sewram V, Ruff P, Freeman M, Asante-Shongwe K. An overview of cancer research in South African academic and research institutions, 2013-2014. S Afr Med J 2016;(6):607610. DOI:10.7196/SAMJ.2016.v106i6.1031

2. Abratt RP. Value of participating in clinical research (Editorial). S Afr Med J 2001;91(7):575

S Afr Med J 2016;106(10):951. DOI:10.7196/SAMJ.2016.v106i10.11220 